\title{
Diurnal Profiles of Plasma Magnesium and Blood Glucose in Diabetes
}

\author{
H. M. Mather ${ }^{1}$, G. E. Levin ${ }^{1}$, J. A. Nisbet ${ }^{1}$, L. A.-A. Hadley ${ }^{2}$, N. W. Oakley ${ }^{2}$ and T. R. E. Pilkington ${ }^{1}$ \\ Departments of Medicine and Chemical Pathology, ${ }^{1}$ St. George's and ${ }^{2}$ St. James Hospitals, London, U. K.
}

Summary. In order to study the relation between plasma magnesium and blood glucose concentrations in diabetes, diurnal profiles were obtained in nine diabetic patients and five healthy subjects. A significant inverse relationship between the two variables was found in seven of the nine diabetic patients and in one healthy subject. This could not be attributed solely to changes in plasma albumin, and its mechanism is unclear. Plasma magnesium levels in diabetes are closely dependent on blood glucose concentration.

Key words: Plasma magnesium, blood glucose, diabetes, diurnal profiles.

Hypomagnesaemia is a relatively common finding in diabetes [1,2] occurring in about $25 \%$ of diabetic outpatients [3]. Its significance is unknown but it may predispose to diabetic retinopathy [4]. It is associated with poor diabetic control and a negative correlation has been found between plasma magnesium and blood glucose values in morning samples from 582 diabetic patients [3]. However, little is known of the relationship between these two variables in individual diabetic patients. To investigate this, diurnal profiles of plasma magnesium and blood glucose have been obtained in diabetic patients and healthy subjects.

\section{Subjects and Methods}

\section{Patients}

Diurnal profiles of plasma $\mathrm{Mg}^{2+}$ and blood glucose concentrations were obtained from nine diabetic patients and five healthy subjects. Clinical details are given in Table 1 .

Insulin treated patients were taking twice daily injections of intermediate and short-acting insulin preparations. Patient 3 had Addison's disease, treated with hydrocortisone ( $10 \mathrm{mg}$ twice daily) and

Table 1. Clinical details of diabetic patients and healthy subjects

\begin{tabular}{|c|c|c|c|c|c|c|c|}
\hline \multirow{2}{*}{$\begin{array}{l}\text { Patient } \\
\text { number }\end{array}$} & \multirow{2}{*}{$\begin{array}{l}\text { Age } \\
\text { (years) }\end{array}$} & \multirow[t]{2}{*}{ Sex } & \multirow{2}{*}{$\begin{array}{l}\text { Duration of } \\
\text { diabetes } \\
\text { (years) }\end{array}$} & \multirow{2}{*}{$\begin{array}{l}\% \text { Ideal } \\
\text { body weight }\end{array}$} & \multirow[t]{2}{*}{ Treatment } & \multicolumn{2}{|c|}{ Insulin dosage } \\
\hline & & & & & & $\begin{array}{l}\text { a.m. } \\
\text { (units) }\end{array}$ & $\begin{array}{l}\text { p.m. } \\
\text { (units) }\end{array}$ \\
\hline 1 & 59 & $\mathrm{~F}$ & 13 & 97 & Insulin & $18 / 0$ & $4 / 8$ \\
\hline 2 & 13 & $\mathrm{~F}$ & 1 & 123 & Insulin & $16 / 8$ & $12 / 8$ \\
\hline 3 & 34 & $\mathrm{~F}$ & 15 & 98 & Insulin & $36 / 24$ & $0 / 12$ \\
\hline 4 & 77 & $\mathrm{~F}$ & 27 & 120 & Insulin & $36 / 12$ & $4 / 0$ \\
\hline 5 & 29 & $\mathbf{M}$ & 5 & 93 & Insulin & $16 / 8$ & $16 / 8$ \\
\hline 6 & 23 & $F$ & 4 & 112 & Insulin & $28 / 12$ & $12 / 8$ \\
\hline 7 & 60 & $\mathrm{~F}$ & 15 & 111 & Insulin & $16 / 8$ & $8 / 8$ \\
\hline 8 & 82 & $\mathrm{~F}$ & 14 & 129 & Chlorpropamide $100 \mathrm{mg}$ & & \\
\hline 9 & 83 & $\mathrm{~F}$ & 4 & 110 & Chlorpropamide $250 \mathrm{mg}$ & & \\
\hline 10 & 18 & M & - & 86 & & & \\
\hline 11 & 22 & $\mathbf{M}$ & - & 113 & & & \\
\hline 12 & 25 & $\mathbf{M}$ & - & 94 & & & \\
\hline 13 & 23 & $\mathbf{M}$ & - & 109 & & & \\
\hline 14 & 25 & $\mathrm{~F}$ & - & 108 & & & \\
\hline
\end{tabular}

a Ideal body weight $=$ from Tables of Metropolitan Life Insurance Company (Scientific Tables, 6th ed. Documenta Geigy, p 624)

b Insulin dosage expressed as units of soluble and NPH insulin 


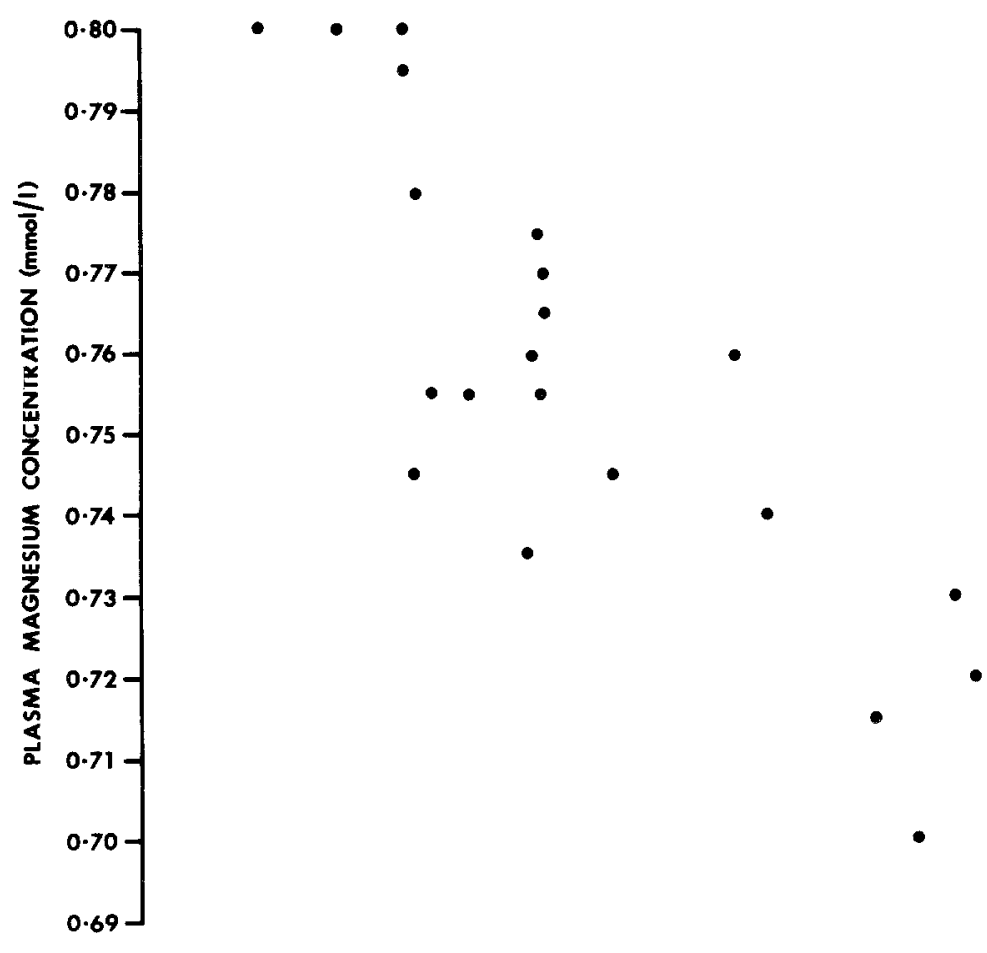

Fig. 1. The relationship between plasma magnesium and blood glucose concentrations within the diumal profile of an insulin treated patient (patient 7).

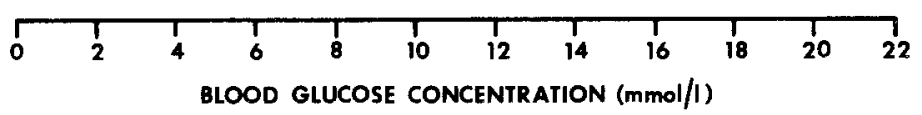

$(r=-0.83, p<0.001)$

Table 2. The mean values of plasma magnesium and blood glucose during the diurnal profiles and the correlation between the two variables

\begin{tabular}{|c|c|c|c|c|}
\hline \multirow{2}{*}{$\begin{array}{l}\text { Patient } \\
\text { number }\end{array}$} & \multirow{2}{*}{$\begin{array}{l}\text { Plasma magnesium } \\
\text { concentration } \\
(\mathrm{mmol} / 1)\end{array}$} & \multirow{2}{*}{$\begin{array}{l}\text { Blood glucose } \\
\text { concentration } \\
(\mathrm{mmol} / \mathrm{l})\end{array}$} & \multicolumn{2}{|c|}{ Correlation } \\
\hline & & & $r$ & $p$ \\
\hline 1 & $0.745 \pm 0.029$ & $8.7 \pm 4.3$ & -0.69 & $<0.001$ \\
\hline 2 & $0.748 \pm 0.020$ & $7.4 \pm 1.9$ & -0.05 & NS \\
\hline 3 & $0.632 \pm 0.040$ & $11.0 \pm 5.0$ & -0.43 & NS \\
\hline 4 & $0.759 \pm 0.028$ & $7.2 \pm 2.7$ & -0.54 & $<0.05$ \\
\hline 5 & $0.784 \pm 0.025$ & $7.6 \pm 4.3$ & -0.73 & $<0.001$ \\
\hline 6 & $0.788 \pm 0.025$ & $9.3 \pm 4.4$ & -0.78 & $<0.001$ \\
\hline 7 & $0.756 \pm 0.028$ & $11.1 \pm 5.1$ & -0.83 & $<0.001$ \\
\hline 8 & $0.585 \pm 0.011$ & $5.0 \pm 1.3$ & -0.73 & $<0.001$ \\
\hline 9 & $0.652 \pm 0.013$ & $12.3 \pm 2.1$ & -0.48 & $<0.05$ \\
\hline 10 & $0.754 \pm 0.018$ & $4.8 \pm 0.9$ & -0.20 & NS \\
\hline 11 & $0.829 \pm 0.025$ & $4.8 \pm 0.7$ & -0.10 & NS \\
\hline 12 & $0.865 \pm 0.034$ & $4.5 \pm 0.8$ & -0.51 & $<0.05$ \\
\hline 13 & $0.756 \pm 0.024$ & $5.0 \pm 1.2$ & -0.41 & NS \\
\hline 14 & $0.747 \pm 0.020$ & $4.8 \pm 0.4$ & 0.00 & NS \\
\hline
\end{tabular}

Results are expressed as mean $\pm \mathrm{SD} ; \mathrm{NS}=$ not significant

fludrocortisone $(0.1 \mathrm{mg}$ once daily). No other diabetic patients had complicating medical disorders, nor were receiving additional drug therapy. None had renal impairment as assessed by plasma creatinine concentration and none had significant diabetic complications, except for patient 4 who had peripheral neuropathy.

\section{Methods}

On the study day, all subjects attended the ward after breakfast and insulin or oral hypoglycaemic therapy as appropriate. An IV cannula was inserted into the median basilic vein and at least 20 blood samples were obtained over a $22-\mathrm{h}$ period at intervals ranging from $30 \mathrm{~min}$ to $2 \mathrm{~h}$. On each occasion $0.5 \mathrm{ml}$ blood was collected into fluoride-oxalate and $10 \mathrm{ml}$ into lithium heparin, from which plasma was separated and stored at $-20^{\circ} \mathrm{C}$. Care was taken to avoid venestasis. Subjects remained either sitting or lying down for at least $10 \mathrm{~min}$ before blood sampling but were otherwise ambulant within the confines of the hospital. Meals were given at 1200, 1800 and $0800 \mathrm{~h}$ and snacks at 1000,1500 and $2200 \mathrm{~h}$. Insulin was administered to the insulin treated diabetic patients at 1730 and $0730 \mathrm{~h}$. All subjects gave their informed consent to the study.

Plasma $\mathrm{Mg}^{2+}$ concentration was estimated by an automated atomic absorption procedure using a Pye-Unicam SP2900 double beam spectrophotometer, on line to a Honeywell 316 computer with a correction applied for drift [5]. Samples from individual patients were estimated in duplicate within the same batch and in random order. The component of variation in plasma $\mathrm{Mg}^{2+}$ due to analytical error was assessed by analysis of the duplicates. The standard deviation of the within batch variation ranged, in different batches, from $0.008-0.015 \mathrm{mmol} / 1$ in the diabetic patients, and from $0.013-0.018 \mathrm{mmol} / 1$ in the healthy subjects. The laboratory normal range for plasma $\mathrm{Mg}^{2+}$ is $0.70-0.92 \mathrm{mmol} / \mathrm{l}$ [3].

Serial plasma albumin and potassium concentrations were measured in duplicate in three diabetic patients (Nos. 5, 6 and 7). Glucose, albumin and potassium assays followed standard Technicon autoanalyser methods. 


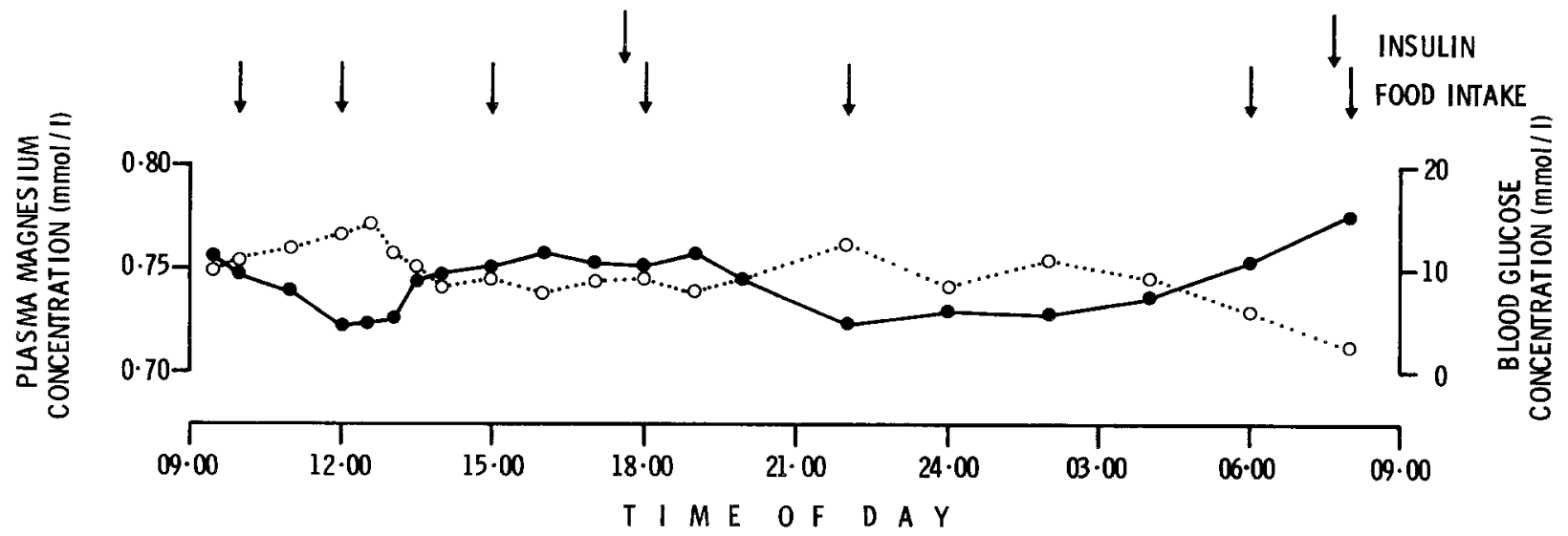

Fig. 2. The mean diurnal profiles of plasma magnesium $(O \ldots$.$) and blood glucose (\longrightarrow)$ concentrations in seven insulin treated diabetic patients

\section{Results}

The data from the diurnal profiles of plasma $\mathrm{Mg}^{2+}$ and blood glucose concentrations in the diabetic patients and healthy subjects are summarised in Table 2. A significant negative correlation was found between plasma $\mathrm{Mg}^{2+}$ and blood glucose in five of the seven insulin treated diabetic patients and in the two patients receiving oral hypoglycaemic therapy. The correlation within one of the insulin treated patients (No.7) is shown in Figure 1. No significant correlation was found either in patient 2 , who showed smaller fluctuations of plasma $\mathrm{Mg}^{2+}$ and blood glucose than the other insulin treated patients, or in patient 3 , who had Addison's disease. In the healthy subjects blood glucose did not vary by more than $4.5 \mathrm{mmol} / 1$, although a significant negative correlation between plasma $\mathrm{Mg}^{2+}$ and blood glucose was found in one subject. The mean diurnal profiles of plasma $\mathrm{Mg}^{2+}$ and blood glucose in the seven insulin treated patients (Fig.2) were obtained by calculating mean values of both variables at each time point. A highly significant negative correlation $(r=-0.82, p=0.001)$ was found between the means of the two variables.

In patients 5,6 and 7, correlation coefficients relating to magnesium, glucose, albumin and potassium were obtained (Table 3). Significant correlations were found between plasma $\mathrm{Mg}^{2+}$ and both albumin and glucose. Multiple regression analyses showed that when the relationship between $\mathrm{Mg}^{2+}$ and albumin had been taken into account, the inverse relationship between $\mathrm{Mg}^{2+}$ and glucose remained highly significant in all three patients. Positive correlations between blood glucose and plasma potassium and a single weak negative correlation between blood glucose and plasma albumin were also found.

The component of individual variability due to analytical error was calculated from the duplicate as-
Table 3. Correlation coefficients within the diurnal profiles of three insulin treated patients

\begin{tabular}{llllll}
\hline $\begin{array}{l}\text { Patient } \\
\text { number }\end{array}$ & $\begin{array}{l}\mathrm{Mg}^{2+} / \\
\text { glucose }\end{array}$ & $\begin{array}{l}\mathrm{Mg}^{2+} / \\
\text { albumin }\end{array}$ & $\begin{array}{l}\mathrm{Mg}^{2+} / \\
\text { potassium }\end{array}$ & $\begin{array}{l}\text { Glucose/ } \\
\text { albumin }\end{array}$ & $\begin{array}{l}\text { Glucose/ } \\
\text { potassium }\end{array}$ \\
\hline 5 & $-0.73^{\mathrm{a}}$ & $0.61^{\mathrm{b}}$ & -0.26 & -0.33 & $0.66^{\mathrm{a}}$ \\
6 & $-0.78^{\mathrm{a}}$ & $0.58^{\mathrm{b}}$ & -0.37 & -0.20 & $0.46^{\mathrm{c}}$ \\
7 & $-0.83^{\mathrm{a}}$ & $0.45^{\mathrm{c}}$ & $-0.53^{\mathrm{c}}$ & $-0.43^{\mathrm{c}}$ & $0.66^{\mathrm{a}}$ \\
\hline
\end{tabular}

${ }^{\mathrm{a}}=p<0.001 ; \quad \mathrm{b}=p<0.01 ;{ }^{\mathrm{c}}=p<0.05$

says. Observed fluctuations in plasma $\mathrm{Mg}^{2+}$ could be attributed either to analytical factors, or to an additional 'biological' component by deriving the ratio of overall to analytical variance. The variance ratio was considerably larger in the diabetic patients than in the control subjects. This was consistent with a significant biological component of variation in seven of the eight diabetic patients, in which data were available, and in three of the five healthy subjects. In the remaining two controls, no significant biological component of variation could be demonstrated.

\section{Discussion}

The principal finding in this study was the strong inverse relationship between plasma magnesium and blood glucose observed in most of the diabetic patients. This has not been described previously in diabetes. In non-diabetic obese children and adolescents, a significant fall in mean serum magnesium concentration has been reported following an oral glucose load, but a smaller decline was found in patients who had impaired glucose tolerance [6]. In contrast with the present study, the mean serum magnesium concentration was unchanged following oral glucose in Japanese non-insulin-dependent (Type 2) diabetic patients [7]. 
The mechanism of the inverse relationship between plasma magnesium and blood glucose in diabetes is unclear. The administration of insulin and glucose to non-diabetic subjects may lower plasma magnesium concentration [8] and insulin may enhance tissue uptake of magnesium $[9,10]$. However, in the present study, plasma magnesium concentrations tended to rise slightly following insulin therapy.

Plasma magnesium may be influenced by alterations in plasma albumin, since it is about $30 \%$ proteinbound, mainly to the albumin fraction [11]. However, multiple regression analyses showed that the relationship between blood glucose and plasma magnesium could not be entirely attributed to concurrent changes in plasma albumin. Further work is required to determine whether plasma ionised or ultrafilterable magnesium also varies inversely with blood glucose in diabetes.

Fluctuations in the net renal excretion of magnesium may also influence the variability of plasma magnesium. We have evidence that $24 \mathrm{~h}$ urinary magnesium is somewhat greater in insulin treated diabetic patients than in healthy subjects, despite significantly lower plasma magnesium concentrations in the former group [12]. This indicates that the usual interrelationship between plasma magnesium concentration and urinary magnesium content [13] is altered in diabetes, but additional short-term studies are required to evaluate this further.

The variability of plasma magnesium in the healthy subjects was no smaller than in the diabetic patients. This was unexpected, because of the relation with blood glucose in the latter group, but may be accounted for by the larger analytical component of variation in the healthy subjects than in the diabetic patients.

We have shown previously [3], that there is a significant negative correlation between plasma magnesium and blood glucose values in samples from a large diabetic clinic population. This study shows that the relationship also pertains within individual diabetic patients. The relevance of these findings to the mechanism and the prevalence of hypomagnesaemia in diabetes is not entirely clear, partly because only one of the insulin treated patients in this study was unequivocally hypomagnesaemic. The implication of these results is that improvement in diabetic control might be associated with an increase in plasma magnesium concentration and possibly decrease the prevalence of hypomagnesaemia. Whether or not this confers any benefit, as has been suggested [14], is currently unknown.
Acknowledgements. We thank Nurse J.Lynch for much practical help, Miss J. Keogh for dietetic supervision, Dr. J.M. Bland and Miss P. A. Bailey for statistical assistance and Professor J. A. Owen for invaluable advice and criticism. HMM received a grant from the British Diabetic Association, and further financial support was provided by Roussel Laboratories Ltd.

\section{References}

1. Stutzman FL, Amatuzio DS (1953) Blood serum magnesium in portal cirrhosis and diabetes mellitus. J Lab Clin Med 41: 215-219

2. Jackson CE, Meier DW (1968) Routine serum magnesium analysis: correlation with clinical state in 5,100 patients. Ann Intern Med 69: 743-748

3. Mather HM, NisbetJA, Burton GH, PostonGJ, BlandJM, Bailey PA, Pilkington TRE (1979) Hypomagnesaemia in diabetes. Clin Chim Acta 95: 235-242

4. McNair P, Christiansen C, MadsbadS, Lauritzen E, FaberO, Binder C, Transbøl I (1978) Hypomagnesaemia, a risk factor in diabetic retinopathy. Diabetes 27: 1075-1077

5. Nisbet JA, Owen JA (1978) Calibration drift in the automated determination of calcium and magnesium by atomic absorption. Clin Chim Acta 92:367-371

6. Rosenbloom A L (1977) Serum calcium and magnesium decline during oral glucose tolerance testing in children and adolescents with preclinical diabetes mellitus less than in normals. Metabolism 26: 1033-1039

7. Ishigami R, Shiotani S, Yoshida A, Kawata T, Notori H, Akiyama Y, OmotoJ, OkadaH (1967) Studies on drug diabetes. Ninth report. Magnesium and carbohydrate metabolism. Jpn Arch Intern Med 14: 131-137

8. Whang R, Wagner R, Rodgers D (1966) The effect of intravenous insulin and glucose on serum $\mathrm{Mg}$ and $\mathrm{K}$ concentration. Clin Res 14: 390

9. Aikawa J K (1960) Effect of glucose and insulin on magnesium metabolism in rabbits. A study with ${ }^{28} \mathrm{Mg}$. Proc Soc Exp Biol Med 103:363-366

10. Lostroh AJ, Krahl ME (1973) Insulin action. Accumulation in vitro of $\mathrm{Mg}^{2+}$ and $\mathrm{K}^{+}$in rat uterus: ion pump activity. Biochim Biophys Acta 291:260-268

11. Cummings NA, KuffEL, SoberHA (1968) Examination of magnesium binding to serum proteins by ultracentrifugal analysis. Anal Biochem 22: 108-116

12. Mather H M (1980) Studies on the magnesium status of diabetic patients. M. D. Thesis, Cambridge University

13. Nordin BEC (1976) Plasma calcium and plasma magnesium homeostasis. In: Nordin BEC (ed) Calcium, phosphate and magnesium metabolism. Churchill Livingstone, Edinburgh London New York, pp 208-216

14. Anonymous (1979) Hypomagnesaemia and diabetic retinopathy. Lancet 1:762

Received: 12 March 1981

and in revised form: 14 October 1981

Dr. H. M. Mather

Department of Medicine 2

St. George's Hospital Medical School

Cranmer Terrace

London SW17 ORE, UK 